\title{
Meaning in life in cancer patients: relationships with illness perception and global meaning changes
}

\begin{abstract}
BACKGROUND
Meaning in life seems to play an important role at various stages of coping in cancer patients. It can influence the ways in which cancer patients perceive their illness and potential changes in beliefs and goals. The main aim of the current study is to examine how two dimensions - presence of and search for meaning - are related to illness perception and global meaning changes.
\end{abstract}

\section{PARTICIPANTS AND PROCEDURE}

The research was conducted among 231 cancer patients (136 women and 95 men), between 27 and 86 years of age $(M=56.73, S D=12.64)$. They were diagnosed with gastrointestinal cancer (stomach, colon, pancreas, liver, large intestine). The following research methods were used: the Meaning in Life Questionnaire, the Appraisal of the Disease Scale, and the Scale of Changes in Beliefs and Goals.

\section{RESULTS}

Presence of meaning was associated with illness perceptions, changes of beliefs, and changes of goals. In contrast, there were no statistically significant relations between search for meaning and illness perception. The cluster analysis showed that the patients who were in presence style less negatively perceived their illness than those in presence and search style. The former also experienced fewer disruptions in important beliefs and goals than the latter. In addition, the patients in presence style were characterized by less negative illness perceptions and fewer disruptions in beliefs and goals than their compeers in indifferent style.

\section{CONCLUSIONS}

Having meaning in life is related to a more satisfactory image of the illness and fewer violations in the belief and goal system. Searching for meaning, even though accompanied by presence of meaning, is rather detrimental to illness perception and changes in beliefs and goals. The awareness of having a purpose and overarching aim in life helps cancer patients to interpret and organize their stressful experiences, and perceive the illness from a less negative perspective.

\section{KEY WORDS}

meaning in life; cancer; illness perceptions; beliefs and goals

ORGANisAtion - 1: Opole University, Opole, Poland · 2: Cancer Center and Institute of Oncology, Gliwice, Poland Authors' Contributions - A: Study design - B: Data collection - C: Statistical analysis - D: Data interpretation .

E: Manuscript preparation · F: Literature search · G: Funds collection

CORRESPONDING AUthor - Prof. Dariusz Krok, Opole University, 1a Drzymały Str., 45-342 Opole, Poland,

e-mail:dkrok@uni.opole.pl

TO CITE THIS ARTICLE - Krok, D., \& Telka, E. (2018). Meaning in life in cancer patients: relationships with illness perception and global meaning changes. Health Psychology Report, 6(2), 171-182. doi: https://doi.org/10.5114/ hpr.2018.71636

RECEIVED 13.02.2017 · REVIEWED 12.05.2017 · ACCEPTED 30.05.2017 • PUBLISHED 07.12.2017 


\section{BACKGROUND}

The evidence linking various aspects of personality traits with illness perception and health, especially in the context of meaning in life, has proliferated in the past few years (Czekierda, Gancarczyk, \& Luszczynska, 2014; Steger, Fitch-Martin, Donnelly, \& Rickard, 2015; Triplett et al., 2012). Extensive research has also documented the importance of meaning structures in cancer patients, who often try to make sense of
Dariusz Krok, Ewa Telka their difficult and challenging experiences by relying on important beliefs and goals (Tomás-Sábado et al., 2015; Winger, Adams, \& Mosher, 2016). Meaning of life has been traditionally understood as an experience of purpose and coherence in one's life, the pursuit and attainment of worthwhile goals, and an accompanying sense of fulfillment (Baumeister, 1991; Frankl, 1969; Reker, 2005). This approach highlights the fact that individuals have a sense of meaning in life when they are convinced about the meaning and purpose of their own lives.

Nowadays, meaning in life is examined as a set of cognitive skills, such as making attributions of purpose and meaning, and finding intentionality in their personal life. It is predominantly assumed to be cognitive in nature, although an emotional component may influence the ways in which individuals think of their beliefs and goals. Steger (2012a) conceptualizes meaning in life as the extent to which individuals comprehend, make sense of, or perceive significance in their lives. This conviction is complemented with the degree to which individuals see themselves as having a purpose, mission, or overarching aims. This conceptualization views meaning in life as a cognitive personality trait that is primarily rooted in human cognition and differs between individuals. According to Steger and his collaborators (Steger, Frazier, Oishi, \& Kaler, 2006) meaning in life has two fundamental dimensions: presence of meaning in life and search for meaning in life. The presence factor represents the degree to which individuals perceive their lives as significant and meaningful, and the search factor denotes the degree to which people are engaged in a search for meaning in life.

Research demonstrated a distinction between having meaning and searching for meaning in relation to various indicators of health and well-being (Steger, 2009, 2012b). Positive associations were found between search for meaning and psychological distress, anxiety and depression, and negative correlations between search for meaning and well-being indicators such as life satisfaction (Park, 2010; Steger, Kashdan, Sullivan, \& Lorentz, 2008). At the same time, studies also showed that search for meaning is not related to distress and a lack of well-being among people who also feel life is highly meaningful (Cohen \& Cairns, 2012; Steger et al., 2008). Krok (2015a) found posi- tive associations between presence of meaning and psychological well-being. In contrast, there was no significant association between search for meaning and psychological well-being. Although the results indicate that meaning in life is beneficial to health and well-being, it is not clear how its different dimensions may relate to specific indicators of health.

There is empirical evidence that meaning in life plays an important role at various stages of coping in cancer patients (Park, 2013a; Winger, Adams, $\&$ Mosher, 2016). The current paper focuses on patients with gastrointestinal (GI) cancer, which is a term depicting the group of cancers that affect the digestive system. This comprises cancers of the esophagus, gallbladder, liver, pancreas, stomach, small intestine, bowel, and anus. Gastrointestinal cancer is a relatively coherent form of cancer from a pathophysiological and clinical perspective (Jeziorski, 2015; Weinberg, 2014). Research on gastrointestinal cancer showed that $72 \%$ of survivors experienced anxiety and fear. In addition to the standard medical treatment, they also needed systematic support to improve quality of life and address the issues of anxiety and depression (Kohno et al., 2010).

Analysing the role of meaning in life in psychotherapy for patients with advanced cancer Breitbart and his colleagues (2010) found that meaning structures were conducive to reducing the level of anxiety and desire for death. Meaning in life was found to be a potentially beneficial factor for patients' emotional suffering at the end of life. Research on palliative care patients demonstrated that cancer patients rely on meaning in life as they cope with their illness and its distressing constraints at the end of their life (Fegg et al., 2010). Compared with the representative sample, palliative care patients reported significantly more meaning in life-relevant areas. This could be a consequence of meaning-based coping processes occurring after the diagnosis of an incurable disease. Yet, the study also revealed that the patients derive meaning in life from different life areas and to a various extent. Examining meaning making processes in cancer survivors Park (2013a) stated that meaning structures play an essential role in the ways in which individuals deal with stressful situations, influencing their adjustment and coping strategies. Both global and situational levels of meaning were positively involved in coping with cancer.

The above results indicating that meaning in life may influence the ways in which cancer patients perceive their illness can be explained within the framework of the Common Sense Model of Self-regulation developed by Leventhal and his collaborators (Leventhal, Meyer, \& Nerenz, 1980; Leventhal, Leventhal, \& Breland, 2011). Meaning in life appears to be linked with illness perception in cancer patients due to the internal functions served by meaning structures. They enable the patients to interpret illness-related 
experiences, identify important aspects of their mental and physical health, and effectively employ coping strategies in accordance with personal resources and situational factors (Park, 2013a).

According to the above model, people make sense out of health threats by forming their own cognitive representations about the illness and its treatment. It occurs on the basis of information obtained from both external sources (i.e. health care professionals, family/friends, and media) and previous experiences with the illness. These cognitive representations or illness perceptions are generally formulated around the following dimensions: identity (the 'label' of the illness and its symptoms), cause (causal beliefs), timeline (acute-chronic or cyclical), control (the extent to which the illness is perceived as modifiable by personal or treatment control), consequences (for the patient's life), coherence (patients' understanding of the illness), and emotional representations (symptoms of anxiety or depression) (Leventhal et al., 2005). The model suggests that individuals actively process cognitive and emotional information related to their illness. In this context meaning in life may play a positive role as a cognitive schema which enables cancer patients to identify and reinterpret all types of information in a self-enhancing way. This process will provide adequate information that is beneficial for the patients to understand their health status and life conditions. In addition, it can also induce positive emotions which are especially valuable in times of serious illness. Empirical studies demonstrated that illness perceptions acted as a framework for coping strategies and influenced health and well-being indicators in cancer patients (Hopman \& Rijken, 2015; Husson et al., 2013).

The connections between meaning in life, illness perception, and global meaning changes can be better understood in the context of the meaning-making model, which has been successfully applied in the field of health (Park, 2013b; Park \& George, 2013). The model posits that individuals possess orienting systems which provide them with cognitive frameworks enabling them to interpret their experiences and with motivation strengthening personal resources. When people encounter stressful situations (e.g. serious illness), they appraise the situations and assign meaning to them.

The model proposes two levels of meaning: global and situational (Park, 2010, 2013b). Global meaning reflects individuals' general orienting systems and perception of various situations, and consists of beliefs, goals, and subjective feelings. It is constructed early in life and modified on the basis of personal experiences. Being strongly connected to motivation global meaning can influence individuals' thoughts, actions, and emotional responses. Situational meaning relates to meaning in the context of specific environmental events. It consists of initial appraisals of the situation and the outcomes of revising global and appraised meanings. Situational meaning is generated at the onset of a potentially stressful event and influences the ways in which individuals deal with their stress.

According to the model, individuals' perception of discrepancies between their appraised meaning of a specific situation and their global meaning generates distress, which entails efforts to reduce the discrepancy and ensuing stress (Park, 2010, Park $\&$ George, 2013). Meaning making represents processes in which people engage to reduce the discrepancy between appraised and global meaning. The processes may involve: (1) changing either situational appraised meaning or global beliefs and goals, (2) searching for a more favourable understanding of the situation and its implications, and (3) reconsidering global beliefs and revising one's meaning in life. All the processes may occur in the context of serious illness and lead to either positive or negative consequences for mental adjustment.

Research conducted by Park (2013a) demonstrated that both global and situational levels of meaning were positively involved in coping with cancer. The patients used both types of meaning to adjust to their health conditions. Testing the Meaning-Making model Steger, Owens and Park (2015) found that stress severity was linked to violations of beliefs and goals. Presence of and search for meaning carried a portion of the indirect effects between goal violations and both posttraumatic stress disorder and stress-related growth. The results imply that traumatic stress (e.g. caused by chronic illness) may disrupt people's goals and meaning-making may be based on these disruptions.

Although empirical studies have examined the relationships between meaning in life and illness perception, little attention has been paid to the systematic study of the underlying mechanisms and also connections with global meaning changes among cancer patients. Previous research evidently demonstrated that meaning in life is associated with psychological processes in cancer (Park, Edmondson, Fenster, \& Blank, 2008). Results demonstrated that meaning structures played an important role in well-being and health-related quality of life among gastrointestinal cancer survivors (Salsman, Yost, West, \& Cella, 2011). However, those studies did not examine whether the dimensions of meaning in life presence of and search for meaning - could be related to illness perception and global meaning changes in the scope of beliefs and goals.

\section{THE PRESENT STUDY}

In summary, the research evidence to date provides the rationale for the model proposed in the present
Meaning in life in cancer patients 
Dariusz Krok, Ewa Telka study, in which we examine the relationships between meaning in life, illness perception, and global meaning changes among cancer patients. The main aim is to assess how two dimensions - presence of and search for meaning - are related to illness perception and global meaning changes. Based on the current research, the following hypotheses were formulated: (1) Presence of meaning is associated with illness perception, while search for meaning has no association, (2) Cancer patients with a relatively high level of presence of meaning have better illness perception and smaller global meaning changes than those with a high level of search for meaning; (3) Cancer patients characterized by a relatively high level of presence of meaning have better illness perception and smaller global meaning changes than those with lower levels of presence of and search for meaning.

\section{PARTICIPANTS AND PROCEDURE}

\section{PARTICIPANTS}

Two hundred and thirty-one cancer patients (136 women and 95 men) participated in this study. Their ages ranged from 27 to 86 years $(M=56.73$, $S D=12.64)$. The data were collected in oncological hospitals and medical centres in which cancer patients were undergoing their treatment. Inclusion/ exclusion criteria - we evaluated patients who were diagnosed with gastrointestinal cancer from min. 1 month; all diagnoses were clinically consulted with an oncologist and confirmed by the patients' medical history; the patients had radical treatment applied with the intention of complete recovery; the patients did not have any symptoms of mental illness; we excluded patients with terminal stage of cancer, when curative treatment was not possible. Cancer sites in the sample were esophagus $(15.00 \%)$, stomach $(23.00 \%)$, pancreas $(18.00 \%)$, liver $(15.00 \%)$, colon $(20.00 \%)$, and small intestine $(9.00 \%)$. The majority of the participants were married or cohabiting with a partner $(80.30 \%)$. They were diagnosed with gastrointestinal cancer from 1 month to 12 years $(M=3.26, S D=2.98)$.

\section{PROCEDURE}

The study was approved by the institutional ethics committee. It was anonymous and all the patients were invited to participate in the study on a voluntary basis. After obtaining informed consent, participants received an envelope containing detailed instructions and a questionnaire packet. They were asked to complete the questionnaire packet either in the hospital room or at home. Afterwards, the closed envelopes with questionnaires were collected by research assistants. After completing the questionnaires the participants were informed about the aim of the study.

Three questionnaires were used in the current research. The Meaning in Life Questionnaire (MLQ) (Steger et al., 2006) is a 10-item questionnaire that measures meaning in life understood as the extent to which people comprehend, make sense of, or see significance in their lives. The questionnaire includes two dimensions of meaning in life: (1) presence of meaning - it denotes the extent to which individuals perceive their lives as meaningful, and (2) search for meaning - it represents the extent to which individuals are actively seeking meaning or purpose in their lives. The items are rated on a 7-point Likert scale, ranging from 1 (not at all) to 7 (very much so). The Cronbach $\alpha$ coefficients for the presence and search subscales in the current study were .82 and .83 , respectively. The MLQ Polish version adapted by Krok (2011) was used.

Illness perception was measured by The Appraisal of the Disease Scale (Janowski, Steuden, Kuryłowicz, \& Nieśpiałowska-Steuden, 2009). It is a 47 -item multidimensional questionnaire which measures the modes of perception of one's own disease. The theoretical background for the tool was provided by Lazarus and Folkman's conception of primary appraisal of the situation in the stress transaction and supplemented by Lipowski's approach to perception of the disease. The scale consists of seven subscales including six thematic: (1) threat - it denotes events that disrupt the person's balance and safety, (2) profit - it represents gains derived from the illness, (3) obstacle/loss - the illness is perceived in terms of difficulty and costs, (4) challenge - it reflects the extent to which the illness is perceived as a challenging situation, (5) harm - the illness is treated in the category of a random event of life which is unfair and harmful, (6) value - the illness is understood as something valuable and beneficial, and (7) importance - it denotes how much illness remains a vital life event for the patient. The items are assessed on a 5-point Likert scale, ranging from 1 (no) to 7 (yes). The reliability coefficients for particular subscales in the current study ranged from .64 to .87 .

Global meaning changes were measured by The Scale of Changes in Beliefs and Goals (Krok, 2016). The scale was developed to assess belief and goal changes that occur during serious illnesses. It reflects the extent to which an illness violates one's beliefs (convictions about various aspects of the world and oneself) and goals (desired results or possible outcomes that a person intends to achieve or accomplish) by changing the person's global meaning system. According to the meaning making theory global meaning reflects individuals' general orienting systems and perception of various situations, and con- 
sists of beliefs, goals, and subjective feelings (Park, 2010, 2013b). The scale includes two subscales: Belief change and Goal change. The belief change subscale contains 8 items measuring how much the illness changed one's beliefs about various aspects of the world and oneself e.g. fairness in the world, ways of perceiving the world, the person's efficacy or competence. The goal change subscale comprises 12 goals which can be violated in the course of illness, e.g. physical health, family relations, personal life, material goods or self-acceptance. The reliability coefficients for the belief change and goal change subscales in the current study were .88 and .90 , respectively.

\section{RESULTS}

In the first step of statistical analyses, correlations were computed among meaning in life, illness perception, and global meaning changes. Table 1 displays the correlations for the study variables.

Presence of meaning was negatively correlated with obstacle/loss, harm, changes of beliefs, and changes of goals, but it was positively correlated with profit, challenge, value, and importance. The only dimension of illness perception that did not show any statistically significant relations was threat. In contrast, there was no statistically significant relation between search for meaning and illness perception. Search for meaning only correlated positively with two dimensions of global meaning changes: changes of beliefs and changes of goals.

To assess the relative contribution of meaning in life dimensions to illness perception and global meaning changes, multiple linear regression analysis was conducted (Table 2). The predictors were presence of meaning and search for meaning, and the dependent variables were, separately: threat, profit, obstacle/loss, challenge, harm, value, importance, changes of beliefs, and changes of goals.

The result of the first regression equation was insignificant $(F=1.64, p=.197)$. In the second regression equation, the combined meaning predictors accounted for $4.00 \%$ of variance in profit $(F=5.57$, $p=.011)$. Examination of the beta weights revealed that presence of meaning predicted higher levels of profit derived from illness. In the regression equation for obstacle/loss, both predictors - presence of meaning and search for meaning - accounted for $6.00 \%$ of variation $(F=7.54, p<.001)$, with presence of meaning predicting lower levels of obstacle/loss, and search for meaning predicting higher levels of obstacle/loss. For challenge, the proportion of variance explained was $5.00 \%$. The beta weights showed that only presence of meaning predicted higher levels of challenge. In the regression equation for harm, both predictors - presence of meaning and search for meaning - accounted for $14.00 \%$ of variation $(F=18.24, p<.001)$, with presence of meaning predicting lower levels of mental damage caused by illness, and search for meaning predicting higher levels of mental damage. The results of the regression equations for value and importance were insignificant (respectively: $F=2.48, p=.085, F=2.10, p=.124$ ).

As regards the dimensions of global meaning changes, in the first regression equation for changes of beliefs, both predictors - presence of meaning and search for meaning - accounted for $6.00 \%$ of variation $(F=7.67, p<.001)$, with presence of meaning predicting lower levels of changes in the belief system, and search for meaning predicting higher levels of changes in beliefs. In the regression equation for changes of goals, the proportion of variance explained was $11.00 \%(F=13.09, p<.001)$, with presence of meaning

\section{Table 1}

Correlations among meaning in life, illness perception, and global meaning changes

\begin{tabular}{lccc}
\hline & & \multicolumn{2}{c}{ Meaning in life } \\
\cline { 2 - 3 } $\begin{array}{l}\text { Illness } \\
\text { perception }\end{array}$ & Threat & Presence of meaning & Search for meaning \\
& Profit & -.10 & .06 \\
Obstacle/loss & $.19^{* *}$ & .03 \\
Challenge & $-.21^{* *}$ & .11 \\
Harm & $.23^{* * *}$ & .06 \\
Value & $-.35^{* * *}$ & .09 \\
$\begin{array}{l}\text { Global } \\
\text { meaning } \\
\text { changes }\end{array}$ & Importance & $.14^{*}$ & .06 \\
\hline Changes of beliefs & $.13^{*}$ & .03 \\
Changes of goals & $-.17^{* *}$ & $.16^{*}$ \\
\hline
\end{tabular}

Note. ${ }^{*} p<.05 .{ }^{* *} p<.01 .{ }^{* * *} p<.001$. 
Table 2

Regression analysis statistics for illness perception and global meaning changes scales on dimensions of presence of meaning and search for meaning

\begin{tabular}{|c|c|c|c|}
\hline & $\beta$ & $t$ & $p$ \\
\hline \multicolumn{4}{|c|}{$\begin{array}{l}\text { Threat: } \\
R=.12, R^{2}=.02, F(2,228)=1.64, p=.197\end{array}$} \\
\hline Presence of meaning & -.10 & -1.56 & .118 \\
\hline Search for meaning & .07 & 1.07 & .286 \\
\hline \multicolumn{4}{|c|}{$\begin{array}{l}\text { Profit: } \\
R=.20, R^{2}=.04, F(2,228)=4.57, p=.011\end{array}$} \\
\hline Presence of meaning & .20 & 2.98 & .003 \\
\hline Search for meaning & .05 & 0.78 & .434 \\
\hline \multicolumn{4}{|c|}{$\begin{array}{l}\text { Obstacle/loss: } \\
R=.25, R^{2}=.06, F(2,228)=7.54, p<.001\end{array}$} \\
\hline Presence of meaning & -.23 & -3.47 & $<.001$ \\
\hline Search for meaning & .14 & 2.08 & .036 \\
\hline \multicolumn{4}{|c|}{$\begin{array}{l}\text { Challenge: } \\
R=.23, R^{2}=.05, F(2,228)=6.31, p=.002\end{array}$} \\
\hline Presence of meaning & .22 & 3.44 & $<.001$ \\
\hline Search for meaning & .03 & 0.51 & .611 \\
\hline \multicolumn{4}{|c|}{$\begin{array}{l}\text { Harm: } \\
R=.37, R^{2}=.14, F(2,228)=18.24, p<.001\end{array}$} \\
\hline Presence of meaning & -.36 & -5.85 & $<.001$ \\
\hline Search for meaning & .13 & 2.12 & .034 \\
\hline \multicolumn{4}{|c|}{$\begin{array}{l}\text { Value: } \\
R=.14, R^{2}=.02, F(2,228)=2.48, p=.085\end{array}$} \\
\hline Presence of meaning & .13 & 2.01 & .044 \\
\hline Search for meaning & .04 & 0.73 & .467 \\
\hline \multicolumn{4}{|c|}{$\begin{array}{l}\text { Importance: } \\
R=.13, R^{2}=.02, F(2,228)=2.10, p=.124\end{array}$} \\
\hline Presence of meaning & .12 & 2.00 & .045 \\
\hline Search for meaning & .01 & 0.20 & .841 \\
\hline \multicolumn{4}{|c|}{$\begin{array}{l}\text { Changes of beliefs: } \\
R=.25, R^{2}=.06, F(2,228)=7.67, p<.001\end{array}$} \\
\hline Presence of meaning & -.19 & -2.98 & .003 \\
\hline Search for meaning & .18 & 2.85 & .005 \\
\hline \multicolumn{4}{|c|}{$\begin{array}{l}\text { Changes of goals: } \\
R=.32, R^{2}=.11, F(2,228)=13.09, p<.001\end{array}$} \\
\hline Presence of meaning & -.27 & -4.37 & $<.001$ \\
\hline Search for meaning & .19 & 3.11 & .002 \\
\hline
\end{tabular}

predicting lower levels of changes in goals, and search for meaning predicting higher levels of the changes.

The next research question formulated in this study referred to examining the different patterns of cancer patients of having and searching for meaning measured by the MLQ scales, and then assessing their effects on the dimensions of illness perception and global meaning changes. Cluster 
analysis was used to enable the identification of different styles of meaning in life. Two scale measures, i.e., presence of meaning and search for meaning, were used as grouping variables. A nonhierarchical k-means cluster analysis was conducted, specifying a three-cluster solution. Interpretive criteria are based on dividing the total sample distribution on each scale into threes. Scores of means, standard deviations, and ANOVA results for three cluster groups representing the three meaning in life styles are presented in Table 3. Cluster 1 - presence and search style (PSS). This cluster group $(n=88)$ was characterized by high scores on both presence of meaning and search for meaning. Cluster 2 - presence style (PS). This cluster group $(n=65)$ demonstrated high scores on presence of meaning and low scores on search for meaning. Cluster 3 - indifferent style (IS). This cluster group $(n=78)$ was characterized by medium scores on both presence of meaning and search for meaning.
One-way ANOVA was used to test for group differences in the proportion of individuals grouped into each cluster for both dimensions of meaning in life. The results for all the dimensions were significant - see Table 3. It confirms differences between the three styles of meaning in life.

In the next step, the effects of the three styles of meaning in life, represented by cluster groups of cancer patients from the present sample, on the dimensions of illness perception and global meaning changes were calculated (Table 4).

The results of the one-way ANOVA test were insignificant in the effects of the styles of meaning in life on threat $(F=1.31, p=.271)$. For profit, the results of one-way ANOVA test revealed significant differences in the effects of the styles of meaning in life $(F=6.94, p<.001)$. Post-hoc comparisons using the Tukey test indicated that presence style was significantly higher than indifferent style. The ANOVA results demonstrated significant differences in the ef-
Meaning in life in cancer patients

Table 3

Means, standard deviations, and the ANOVA results for three styles of meaning in life

\begin{tabular}{|c|c|c|c|c|c|c|c|c|}
\hline & \multicolumn{2}{|c|}{$\begin{array}{c}\text { Presence and } \\
\text { search style PSS }\end{array}$} & \multicolumn{2}{|c|}{$\begin{array}{c}\text { Presence style } \\
\text { PS }\end{array}$} & \multicolumn{2}{|c|}{$\begin{array}{c}\text { Indifferent style } \\
\text { IS }\end{array}$} & \multirow[t]{2}{*}{$F$} & \multirow[t]{2}{*}{$p$} \\
\hline & $M$ & $S D$ & $M$ & $S D$ & $M$ & $S D$ & & \\
\hline Presence of meaning & 5.34 & 0.78 & 5.51 & 0.74 & 3.52 & 0.65 & 176.46 & $<.001$ \\
\hline Search for meaning & 5.22 & 0.69 & 3.15 & 0.65 & 3.94 & 1.06 & 123.07 & $<.001$ \\
\hline
\end{tabular}

Table 4

Means, standard deviations, and the ANOVA effects for the dimensions of illness perception and global meaning changes between styles of meaning in life

\begin{tabular}{|c|c|c|c|c|c|c|c|c|c|}
\hline & \multicolumn{2}{|c|}{$\begin{array}{c}\text { Presence and } \\
\text { search style PSS }\end{array}$} & \multicolumn{2}{|c|}{$\begin{array}{c}\text { Presence style } \\
\text { PS } \\
\end{array}$} & \multicolumn{2}{|c|}{$\begin{array}{l}\text { Indifferent style } \\
\text { IS }\end{array}$} & \multirow[t]{2}{*}{$F$} & \multirow[t]{2}{*}{$p$} & \multirow[t]{2}{*}{$\begin{array}{c}\text { Tukey } \\
\text { test }\end{array}$} \\
\hline & $M$ & $S D$ & $M$ & $S D$ & $M$ & $S D$ & & & \\
\hline Threat & 3.79 & 0.85 & 3.63 & 1.06 & 3.86 & 0.79 & 1.31 & .271 & - \\
\hline Profit & 2.58 & 0.80 & 2.79 & 0.83 & 2.31 & 0.68 & 6.94 & $<.001$ & PS:IS*** \\
\hline Obstacle/loss & 3.21 & 0.91 & 2.74 & 0.98 & 3.33 & 0.79 & 8.40 & $<.001$ & $\begin{array}{l}\text { PSS:PS }{ }^{* *}, \\
\text { PS:IS*** }\end{array}$ \\
\hline Challenge & 3.96 & 0.72 & 3.93 & 0.86 & 3.56 & 0.68 & 6.96 & $<.001$ & $\begin{array}{l}\text { PSS:IS**, } \\
\text { PS:IS** }\end{array}$ \\
\hline Harm & 2.73 & 0.96 & 2.26 & 0.91 & 3.04 & 0.87 & 12.96 & $<.001$ & $\begin{array}{l}\text { PSS:PS**, } \\
\text { PS:IS*** }\end{array}$ \\
\hline Value & 3.25 & 0.82 & 3.21 & 1.03 & 3.00 & 0.80 & 1.98 & .139 & - \\
\hline Importance & 3.68 & 0.86 & 3.75 & 0.80 & 3.59 & 0.81 & 0.69 & .504 & - \\
\hline Changes of beliefs & 2.76 & 1.00 & 2.36 & 0.74 & 2.74 & 0.86 & 4.55 & .012 & $\begin{array}{l}\text { PSS:PS*, } \\
\text { PS:IS* }\end{array}$ \\
\hline Changes of goals & 2.69 & 0.98 & 2.30 & .82 & 2.88 & 0.74 & 8.22 & $<.001$ & $\begin{array}{l}\text { PSS:PS*, } \\
\text { PS:IS*** }\end{array}$ \\
\hline
\end{tabular}

Note. ${ }^{* * *} p<.001 .{ }^{* *} p<.01 .{ }^{*} p<.05$. 
Dariusz Krok, Ewa Telka fects of the styles of meaning in life on obstacle/loss $(F=8.40, p<.001)$. Post-hoc comparisons using the Tukey test indicated that presence and search style and indifferent style were significantly higher than presence style. Similar results in the styles occurred for harm $(F=12.96, p<.010)$, with presence and search style and indifferent style obtaining significantly higher scores than presence style. In contrast, within significant effects of the styles on challenge $(F=6.96, p<.001)$ presence and search style and presence style were significantly higher than indifferent style. There were no statistically significant results for value and importance.

As regards the dimensions of global meaning changes, the results of the one-way ANOVA test revealed significant differences in the effects of the styles of changes of beliefs $(F=4.55, p=.050)$. Posthoc comparisons showed that presence and search style and indifferent style were significantly higher than presence style. Analogous results in the styles occurred for changes of goals $(F=8.22, p<.001)$, with presence and search style and indifferent style obtaining significantly higher scores than presence style.

\section{DISCUSSION}

Experiencing life as meaningful is a vital aspect of positive human functioning that has an impact on the ways in which people perceive their illness. Based on the idea that meaning in life enables ill people to interpret and organize their experience and effectively cope with the illness, we examined the associations between meaning in life, illness perception, and global meaning changes. This study leads to three conclusions. First, the associations between meaning in life, illness perception, and global meaning changes vary, depending on the dimensions of meaning in life. Second, only presence of meaning is associated with illness perception, while search for meaning has no association. However, search for meaning is linked to global meaning changes. Third, the associations between meaning in life, illness perception, and global meaning changes depend on cancer patients having and/or searching for meaning. These results are in line with a functional approach to meaning in life.

\section{MEANING IN LIFE AND ILLNESS ASSESSMENT}

The different types of gastrointestinal cancers are life-threatening diseases which have a strong negative impact on a broad range of psychosocial outcomes for patients, in addition to their physical effects. Meaning in life has been found to be beneficial to adjustment and quality of life in cancer patients, influencing their illness perception (Breitbart et al.,
2010; Malcarne, 2011; Park, 2013a). The findings obtained in the current study revealed that the associations between meaning in life, illness perception, and global meaning changes are not homogeneous, but they depend on the specific dimensions of meaning in life. Presence of meaning was associated with illness perception, in contrast with search for meaning, which had no association. However, there were significant connections between search for meaning and global meaning changes in both dimensions: beliefs and goals.

These results imply that cancer patients who can successfully find meaning in their lives tend to perceive the illness more efficiently in terms of profit, challenge, value, and importance. At the same time they see their illness as obstacle/loss and harm to a lesser extent. Finding meaning in life appears to be thus associated with more optimistic and hopeful perceptions of cancer. It is also connected with less negative changes in beliefs regarding various aspects of the world and oneself and important life goals, e.g. physical health, family relations, personal life or self-acceptance. In contrast, search for meaning was only related to more changes in beliefs and goals, which suggests that cancer patients who do not have firmly established meaning in life are characterized by stronger disruptions in their belief and goal structures. It allows us to verify the first hypothesis which assumed such relationships.

Our findings are consistent with previous results which demonstrated that presence of meaning is a valuable indicator of positive functioning and psychosocial adjustment (Cohen \& Cairns, 2012; Krok, 2015a; Steger et al., 2008), whereas search for meaning is associated with more anxiety and depression (Skaggs et al., 2007). They also extend previous studies regarding meaning in life in cancer patients (Park, 2013a; Winger, Adams, \& Mosher, 2016) by demonstrating that steadily formed meaning in life can be beneficial to the ways in which the patients perceive their health and well-being. It also buffers potential disturbances in belief and goal systems. In this sense, meaning in life helps cancer patients to form more positive views of their illness, interpret important life conditions, and effectively integrate the overall image of the illness. They rely on their mental meaning structures in order to appraise the meaning of the situation.

The results of the current study expand the Common Sense Model of Self-Regulation Processes (Leventhal, Meyer, \& Nerenz, 1980; Leventhal, Leventhal, \& Breland, 2011), which posits that individuals form their own cognitive representations about the illness. Our findings demonstrate that cancer patients must have a satisfactory level of meaning in life if they are to form positive illness perceptions. Search for meaning alone is not a sufficient factor to prevent people with cancer from negative consequences of 
the illness, as it was not connected with the illness perception dimensions. Moreover, search for meaning was related to more negative disruptions in the patients' life beliefs and goals. Although individuals searching for meaning might generally be expected to find it, research suggests that deficits in meaning prompt people to search for meaning (Steger et al., 2008). Reflecting on meaning and purpose, cancer patients need to derive some sense of existential significance from life, which in turn will enable them to form more resilient attitudes to the illness demands and stress.

\section{STYLES OF MEANING IN LIFE AND THE IMAGE OF ILLNESS}

The full understanding of the role played by meaning in life in illness perception and global meaning changes requires taking into consideration both of its dimensions: presence and search. In view of the high psychological needs in gastrointestinal cancer, it is vital to differentiate between patients having and/or searching for meaning. The cluster analysis employed in the current study allowed us to identify three distinct cluster groups, which represent an integrative and nuanced depiction of the patients' experiences of meaning in life: presence and search style, presence style, and indifferent style. The three styles of meaning in life denote different approaches to the sphere of purpose and significance, which is an important factor needed for people with a chronic illness to form a cohesive view of life and cope with negative consequences caused by the illness.

Those patients who were in presence style less negatively perceived their illness as obstacle/loss and harm than those in presence and search style, which confirms the second hypothesis. The former also experienced less damaging disruptions in important life beliefs and goals in comparison with the latter. In addition, the patients in presence style were characterized by less obstacle/loss and harm, fewer disruptions in beliefs and goals, and more profit and challenge in illness perceptions than their compeers in indifferent style. This indicates that when people with cancer already have meaning, they have a solid foundation that allows them to see their illness in a more positive light and experience less detrimental effects in belief and goal systems. In contrast, when the patients have not attained a satisfactory level of meaning in life, their search for meaning or lack of it can be problematic and frustrating, resulting in a more negative image of the illness. It allows us to verify the third hypothesis, which proposed such relationships.

The patterns revealed in the present study are consistent with previous research demonstrating that meaning structures are beneficial to perceiving psychological costs of cancer (Breitbart et al., 2010) and coping with cancer and its distressing constraints (Fegg et al., 2010). For cancer patients, it is essential to find meaning in life in order to avoid negative consequences related to the image of the illness and reduce the likelihood of potential disruptions in their belief and goal systems. Meaning and purpose can help control illness-related stress and foster their mental adjustment.

At the same time, our study sheds new light on previous research as it suggests that search for meaning is rather detrimental to illness perception and global meaning changes in beliefs and goals, even though it is accompanied by presence of meaning (i.e. the presence and search style). Although some studies found that search for meaning was positively associated with greater life satisfaction, more happiness, and less depression among adults with a relatively high level of meaning in life (Park, Park, \& Peterson, 2010), our findings contradict them.

The explanation for this discrepancy may lie in the specific characteristics of research groups. While search for meaning plays a gratifying role among healthy individuals (Park, Park, \& Peterson, 2010) and is conducive to the developmental process of identity exploration in adolescents (Krok, 2015b; Steger, Oishi, \& Kashdan, 2009), it seems to have detrimental effects on people with such a serious chronic illness as cancer. The illness involves an extensive number of cognitive, emotional, and behavioural changes which lead people with cancer to perceive the illness and their own lives in a completely different way than healthy people. This finding is important for future research as it implies that stressful experiences caused by cancer may modify the role played by some dimensions of meaning in life, especially search for meaning.

This interpretation can be understood more deeply within the framework of the Meaning Making Model (Park, 2010, 2013b). According to the model, individuals experience stress when they perceive discrepancies between their global meaning and their appraised meaning of a particular situation, e.g. the illness. This discrepancy causes distress which motivates individuals to resolve their problems and assuage negative emotions. As global meaning reflects individuals' general orienting systems and consists of beliefs, goals, and meaning in life, having a high level of meaning in life can help cancer patients to form a satisfactory image of the illness and minimise the risk of violating life beliefs and goals. Meaning in life can function as a mental resource enabling patients to use positive reappraisals, through which they can interpret the situation in terms of deeply held goals and values and strengthen their sense of control. As a result, it will lead to perceiving the illness and one's life in less negative (harm, loss) and more positive (profit, value) perspectives.
Meaning in life in cancer patients 
Dariusz Krok, Ewa Telka
Our research also bears some practical implications of the findings for counselling cancer patients and their families. Professional staff working in oncological units can strengthen cancer patients' meaning in life by pointing to important life goals and values, which in turn will enable the patients to reinterpret their perceptions of the illness and reduce anxiety. Meaning-oriented interventions directed at finding purpose and intentionality in cancer patients' personal life can lead to their increased awareness and understanding of specific aspects of diagnosis and treatment and effectively reinforce their coping strategies. The interventions are also likely to help family members to understand the patients' cognitive and emotional representations of the illness and address them in the context of purpose and meaning.

\section{LIMITATIONS}

The current study has some limitations that should be addressed. First, the study had a cross-sectional design, which prevents us from formulating conclusions about a causal relationship. Although the Common Sense Model of Self-Regulation Processes could suggest that meaning in life as a personality characteristic influences illness perceptions, future research must test the mediating models using longitudinal studies or a log linear approach. Second, illness perceptions and global meaning changes were measured only once at a time. As we know from research on cancer patients (Husson et al., 2013; Tomás-Sábado et al., 2015), their perception of the illness tends to change in accordance with both internal (illness progression, pain) and external conditions (information about the illness, medical care). Therefore, it would be expedient to assess illness perceptions and global meaning changes at various stages of the illness. Third, the study included patients with gastrointestinal cancer. Though choosing this type of cancer as one research group is justified from a medical point of view, dysfunctions of different organs contained within this category (i.e. stomach, colon, pancreas, liver, or large intestine) are likely to trigger dissimilar reactions.

\section{CONCLUSIONS}

In conclusion, our study provides proof of the relationship between meaning in life, illness perception, and global meaning changes. Having meaning in life is related to a more satisfactory image of the illness and fewer violations in the belief and goal system. Presence of meaning in life can be thus beneficial to the ways in which cancer patients perceive their health and well-being. However, search for meaning, even though accompanied by presence of meaning (i.e. the presence and search style), is rather detrimental to illness perception and global meaning changes in beliefs and goals. The awareness of having a purpose and overarching aim in life helps cancer patients to interpret and organize their stressful experiences, and perceive the illness from a less negative perspective.

\section{References}

Baumeister, R. F. (1991). Meanings of life. New York: Guilford.

Breitbart, W., Rosenfeld, B., Gibson, C., Pessin, H., Poppito, S., Nelson, C., ...Olden, M. (2010). Meaning-centered group psychotherapy for patients with advanced cancer: a pilot randomized controlled trial. Psychooncology, 19, 21-28.

Cohen, K., \& Cairns, D. (2012). Is searching for meaning in life associated with reduced subjective well-being? Confirmation and possible moderators. Journal of Happiness Studies, 13, 313-331.

Czekierda, K., Gancarczyk, A., \& Luszczynska, A. (2014). Associations between meaning in life and health indicators: A systematic review. European Health Psychologist, 16, 432.

Fegg, M. J., Brandstätter, M., Kramer, M., Kögler, M., Haarmann-Doetkotte, S., \& Borasio, G. D. (2010). Meaning in life in palliative care patients. Journal of Pain and Symptom Management, 40, 502-509.

Frankl, V. E. (1969). The will to meaning: Principles and application of logotherapy. New York: New American Library.

Hopman, P., \& Rijken, M. (2015). Illness perceptions of cancer patients: relationships with illness characteristics and coping. Psychooncology, 24, 11-18.

Husson, O., Thong, M. S., Mols, F., Oerlemans, S., Kaptein, A. A., \& Poll-Franse, L. V. (2013). Illness perceptions in cancer survivors: what is the role of information provision? Psychooncology, 22, 490-498.

Janowski, K., Steuden, S., Kuryłowicz, J., \& Nieśpiatowska-Steuden, M. (2009). The Disease-Related Appraisals Scale: a tool to measure subjective perception of the disease situation. In K. Janowski \& S. Steuden (Eds.), Biopsychosocial aspects of health and disease (pp. 108-125). Lublin: CPPP Scientific Press.

Jeziorski, A. (2015). Najczęstsze nowotwory - objawy, rozpoznanie i leczenie [The most common cancers - symptoms, recognition and treatment]. In A. Jeziorski (Ed.), Onkologia. Podręcznik dla pielęgniarek [Oncology. The handbook for nurses] (pp. 93-166). Warszawa: Wydawnictwo Lekarskie PZWL.

Kohno,Y., Maruyama, M., Matsuoka,Y., Matsushita,T., Koeda, M., \& Matsushima, E. (2010). Relationship 
of psychological characteristics and self-efficacy in gastrointestinal cancer survivors. Psychooncology, 19, 71-76.

Krok, D. (2011). Poczucie sensu życia a dobrostan psychiczny [Meaning in life and well-being]. Psychologia Jakości Życia, 10, 95-115.

Krok, D. (2015a). The role of meaning in life within the relations of religious coping and psychological well-being. Journal of Religion and Health, 54, 2292-2308.

Krok, D. (2015b). Religiousness, spirituality, and coping with stress among late adolescents: A meaning-making perspective. Journal of Adolescence, 45, 196-203.

Krok, D. (2016). Skala Zmiany Przekonań i Celów [The Scale of Changes in Beliefs and Goals]. Opole: Katedra Psychologii i Pedagogiki Rodziny.

Leventhal, H., Halm, E., Horowitz, C., Leventhal, E., \& Ozakinci, G. (2005). Living with chronic illness: A contextualized, self-regulation approach. In $\mathrm{S}$. Sutton, A. Baum, \& M. Johnston (Eds.), The Sage handbook of health psychology (pp. 197-240). Londyn: Sage.

Leventhal, H., Leventhal, E. A., \& Breland, J. Y. (2011). Cognitive science speaks to the "common-sense" of chronic illness management. Annals of Behavioral Medicine, 41, 152-163.

Leventhal, H., Meyer, \& D. Nerenz, D. (1980). The common sense model of illness danger. In S. Rachman (Ed.), Contributions to Medical psychology (Vol. 2, pp. 7-30). Pergamon, New York.

Malcarne, V. L. (2011). Coping with cancer. In H. S. Friedman (Ed.), The Oxford handbook of health psychology (pp. 394-416). Oxford: Oxford University Press.

Park, C. L. (2010). Making sense of the meaning literature: An integrative review of meaning making and its effects on adjustment to stressful life events. Psychological Bulletin, 136, 257-301.

Park, C. L. (2013a). Spirituality and meaning making in cancer survivorship. In K. D. Markman, T. Proulx, \& M. J. Lindberg (Eds.), The psychology of meaning (pp. 257-277). Washington: American Psychological Association.

Park, C. L. (2013b). The meaning making model: A framework for understanding meaning, spirituality, and stress-related growth in health psychology. The European Health Psychologist, 15, 40-47.

Park, C. L., \& George, L. S. (2013). Assessing meaning and meaning making in the context of stressful life events: Measurement tools and approaches. The Journal of Positive Psychology, 8, 483-504.

Park, C. L., Edmondson, D., Fenster, J. R., \& Blank, T. O. (2008). Meaning making and psychological adjustment following cancer: The mediating roles of growth, life meaning, and restored just-world beliefs. Journal of Consulting and Clinical Psychology, $76,863-875$.
Park, N., Park, M., \& Peterson, C. (2010). When is the search for meaning related to life satisfaction? Applied Psychology: Health and Well-Being, 2, 1-13.

Reker, G. T. (2005). Meaning in life of young, middle-aged, and older adults: Factorial validity, age, and gender invariance of the Personal Meaning Index (PMI). Personality and Individual Differences, 38, 71-85.

Salsman, J. M., Yost, K. J., West, D. W., \& Cella, D. (2011). Spiritual well-being and health-related quality of life in colorectal cancer: a multi-site examination of the role of personal meaning. Supportive Care in Cancer, 19, 757-764.

Skaggs, B. G., Yates, B. C., Hertzog, M., Barron, C. R., Norman, J., \& Pozehl, B. (2007). Meaning in heart disease: Measuring the search for meaning. Journal of Nursing Measurement, 15, 145-160.

Steger, M. F. (2012a). Experiencing meaning in life: Optimal functioning at the nexus of well-being, psychopathology, and spirituality. In P. T. P. Wong (Ed.), The Human quest for meaning: Theories, research, and applications (pp. 165-184). New York: Routledge.

Steger, M. F. (2012b). Making meaning in life. Psychological Inquiry, 23, 381-385.

Steger, M. F., Fitch-Martin, A. R., Donnelly, J., \& Rickard, K. M. (2015). Meaning in life and health: Proactive health orientation links meaning in life to health variables among American undergraduates. Journal of Happiness Studies, 16, 583-597.

Steger, M. F., Frazier, P., Oishi, S., \& Kaler, M. (2006). The meaning in life questionnaire: Assessing the presence of and search for meaning in life. Journal of Counseling Psychology, 53, 80-93.

Steger, M. F., Kashdan, T. B., Sullivan, B. A., \& Lorentz, D. (2008). Understanding the search for meaning in life: Personality, cognitive style, and the dynamic between seeking and experiencing meaning. Journal of Personality, 76, 199-228.

Steger, M. F., Oishi, S., \& Kashdan, T. B. (2009). Meaning in life across the life span: Levels and correlates of meaning in life from emerging adulthood to older adulthood. The Journal of Positive Psychology, 4, 43-52.

Steger, M. F., Owens, G. P., \& Park, C. L. (2015). Violations of war: Testing the meaning-making model among Vietnam veterans. Journal of Clinical Psychology, 71, 105-116.

Tomás-Sábado, J., Villavicencio-Chávez, C., Monforte-Royo, C., Guerrero-Torrelles, M., Fegg, M. J., $\&$ Balaguer, A. (2015). What gives meaning in life to patients with advanced cancer? A comparison between Spanish, German, and Swiss patients. Journal of Pain and Symptom Management, 50, 861-866.

Triplett, K. N., Tedeschi, R. G., Cann, A., Calhoun, L. G., \& Reeve, C. L. (2012). Posttraumatic growth,
Meaning in life in cancer patients 
meaning in life, and life satisfaction in response to trauma. Psychological Trauma: Theory, Research, Practice, and Policy, 4, 400-410.

Weinberg, R. (2014). The biology of cancer. New York and London: Garland Science.

Winger, J. G., Adams, R. N., \& Mosher, C. E. (2016). Relations of meaning in life and sense of coherence to distress in cancer patients: A meta-analysis. Psycho-Oncology, 25, 2-10.

Dariusz Krok,

Ewa Telka 